\title{
Nota sobre o problema da fundamentação última na Begriffsschrift de Fichte
}

\author{
Juan A. Bonaccini
}

UFRN

resumo Neste trabalho é analisada a estratégia da exposição de Fichte em seu escrito Sobre o conceito da Doutrina da Ciência (1794) e interpretada como indo de encontro a um determinado tipo do ceticismo moderno. Todavia, ao contrário da leitura proposta por Rockmore, que sustenta ser possivel considerar toda a epistemologia fichteana dessa época como uma linha de argumentação de cunho pragmático e antifundacionista, defende-se a tese de que Fichte está comprometido desde o início com a tarefa de uma fundamentação última de toda ciência a partir de um primeiro princípio. Esta fundamentação seria levada a cabo mediante uma demonstração indireta que pretende refutar de modo muito original objeções levantadas por Maimon, por Schulze e outros contra a filosofia transcendental de Kant. 0 mero fato de que Fichte não considerasse este último princípio como passível de demonstração direta não é suficiente para tachar sua estratégia de pragmática.

palavras-chave Fichte; Filosofia Transcendental; Pragmatismo; Ceticismo; Fundacionismo

Para Ana Thereza

\section{À guisa de introdução}

A chamada Begriffsschrift (conhecida entre nós como Sobre o conceito da Doutrina da Ciência... $)^{1}$, uma espécie de escrito programático que Fichte redige aproximadamente entre 1793 e 1794, parece ter sido pensada como um convite a suas aulas, uma sorte de introdução a seu sistema ${ }^{2}$.

Recebido em 9 de outubro de 2006. Aceito em 20 de dezembro de 2006.

doispontos, Curitiba, São Carlos, vol. 4, n. 1, p. 47-61, abril, 2007 
Com efeito, basta uma rápida leitura para perceber que neste opúsculo Fichte ainda não nos apresenta a própria "Doutrina da Ciência" $<$ Wissenschftslehre $>$, mas apenas a exposição preliminar do seu conceito. Tanto é assim que numa carta de outubro de 1794 que enviara a Kant, junto com dois manuscritos para sua apreciação, Fichte referia-se a um deles (presumivelmente a primeira parte da Grundlage de 1794) como à "primeira tentativa de levar a cabo o plano mencionado em meu escrito Sobre o conceito da Doutrina da Ciência" (Fichte a Kant, 6 de outubro de 1794, in: KANT, 1902, XI, p. 526).

Examinando-a mais de perto, entretanto, a Begriffsschrift apresenta-se ao leitor como um escrito sistemático e um projeto de sistema ao mesmo tempo. O que é compreensível, se consideramos o contexto em que foi pensado e redigido, a saber, quando Fichte vai ocupar a antiga cadeira de Reinhold em Iena. Pois, de um lado, a grande maioria dos intelectuais da época estava empenhada na construção de um sistema de filosofia parcialmente inspirado nas recomendações da filosofia crítica, a começar pelo próprio Reinhold. Tratava-se, sobretudo, de superar as dificuldades encontradas na filosofia crítica, quer pelos céticos, quer por aqueles que entendiam a empresa kantiana como uma mera propedêutica ao sistema que o próprio Kant prometera mas não construíra. Fichte não era alheio a esta última preocupação, que herdara do próprio Reinhold.Todavia, seu trabalho ainda não estava suficientemente maduro; e muito embora endossasse com a época a necessidade de construir um sistema de inspiração kantiana, Fichte começara por refletir sobre os escritos de Reihold e Kant, a fim de posteriormente poder traçar o seu próprio plano e apresentar seu projeto de sistema.

De modo que Sobre o conceito... pode ser classificado, juntamente com as Eignen Meditationen über die Elementar-Philosophie (1793) e a polêmica Recension des Aenesidemus (1794), como parte de um grupo de escritos que marcam o despontar da reflexão fichteana sobre o estatuto científico da filosofia e antecedem a primeira versão acabada da Doutrina da Ciência ${ }^{3}$. No entanto, apesar de sua importância histórica, e mesmo conceitual, a Begriffsschrift não tem atraído muita atenção; embora por vezes seja citada ${ }^{4}$. Mencioná-la, ou simplesmente ignorá-la, parece ser um lugar-comum entre os estudiosos de Fichte, que logo em seguida se concentram na análise da Grundlage ${ }^{5}$, da Nova Methodo ${ }^{6}$ e de

doispontos, Curitiba, São Carlos, vol. 4, n. 1, p. 47-61, abril, 2007 
outros escritos e versões posteriores da Doutrina da Ciência ${ }^{7}$. Dada essa circunstância, parece no mínimo interessante chamar a atenção para o próprio texto de Fichte. Mas antes cabe fazer uma ressalva quanto ao escopo desta breve nota.

Não se trata aqui oferecer um comentário detalhado desse escrito (prefiro reservar essa tarefa para outra ocasião). Mas penso que algumas considerações iniciais poderiam chamar a atenção para sua importância, geralmente negligenciada. Sobretudo para compreender a estratégia de Fichte em relação ao problema da fundamentação última <Letztbegrün$d u n g>$, bem como sua originalidade em face de contemporâneos como Reinhold (que fora o primeiro a sustentar que a filosofia de Kant carecia de uma fundamentação a partir de um princípio último) ${ }^{8}$. Todavia, tampouco pretendo comparar a posição de Fichte com a dos defensores de uma fundamentação última na discussão contemporânea ${ }^{9}$. Meu propósito aqui é bem mais modesto: apenas desejaria explicar como e em que medida Fichte teve como meta uma fundamentação última do conhecimento filosófico em seu opúsculo Sobre o conceito da Doutrina da Ciência, ou da assim chamada filosofia. Para tanto me sirvo da análise de algumas passagens do texto em questão e ofereço uma interpretação em contraponto com a leitura "pragmatista" de Tom Rockmore.

\section{Fichte: precursor do pragmatismo?}

Num artigo relativamente recente, Tom Rockmore sugere que as versões da Doutrina da Ciência redigidas entre 1794 e 1799 evidenciariam que Fichte não era um filósofo fundacionista (ROCKMORE, 1995, pp. 107124). Na verdade, sua principal alegação consiste em dizer que durante o período de Iena toda a empresa fichteana tem um caráter explícita e deliberadamente hipotético, razão pela qual não faria mais sentido sustentar que na Doutrina da Ciência de Iena Fichte teria por meta uma fundamentação última do conhecimento. Além disso, Rockmore vai ainda mais longe, chegando a afirmar que ao negar a possibilidade de uma demonstração dedutiva do primeiro princípio do seu sistema, Fichte teria optado por uma estratégia pragmática de argumentação. Numa palavra, ainda que procurasse construir um sistema com base num

doispontos, Curitiba, São Carlos, vol. 4, n. 1, p. 47-61, abril, 2007 
princípio último, Rockmore acha que Fichte pode ser considerado como um precursor do pragmatismo ${ }^{10}$.

Basicamente, porém, creio que discordo da interpretação de Rockmore porque parece apoiar-se numa compreensão pouco clara do que Fichte sustenta ser "hipotético" em seus textos de Iena. Além disso, parece-me que na Begriffsschrift Fichte oferece de fato uma prova dedutiva: o que não oferece é uma prova direta. Por isso, tomando esse texto como exemplo pretendo mostrar que aquilo que Fichte caracteriza como "hipotético" é um tipo de estratégia de argumentação dedutiva e anticéptica, o que não torna hipotético o valor de suas conclusões - e eventualmente poderia até ser considerado como uma espécie sui generis de argumento transcendental.

A fim de que a questão seja posta com clareza, creio que primeiro se deve entender o ponto para o qual Fichte pretende chamar a atenção do leitor logo no início do prefácio à primeira edição da Begriffsschrift: “a investigação a seguir não ergue a pretensão a nenhuma outra validade que não seja hipotética" (FICHTE, 1971, SW, I, p. 30).

Ora, por que e em que sentido Fichte fala aqui de validade "hipotética"? Caberia perguntar se essa advertência implica necessariamente considerar o programa da Wissenschatfslehre como uma mera "hipótese". Se não se trata justamente do contrário, dado o projeto fichteano de uma metaciência que quer explicar e fundamentar a possibilidade da verdade de toda e qualquer ciência. Afinal, Fichte não teria dito apenas que, em face do desafio de céticos como Schulze e Maimon ${ }^{11}$, o curso da argumentação deveria proceder "hipoteticamente", a saber, com um certo cuidado e muita precaução? Dito de outro modo: será que um texto como a Begriffsschrift permitiria afirmar que nesta época Fichte não procurava uma fundamentação última da ciência filosófica? Notadamente: será que a estratégia deste escrito inaugural do período de Iena forneceria uma base de sutentação para a tese de que Fichte teria sido, na verdade, um filósofo "antifundacionista"?

Como foi mencionado acima, Rockmore parece acreditar que a resposta a esta pergunta deveria ser respondida afirmativamente. Por isso defende que o fato de Fichte recorrer à indemonstrabilidade do primeiro princípio seria uma boa razão para tanto (ROCKMORE, 1995, pp. 107-124). Mas isto não me parece que coincida com os textos, nem com o "espírito" da discussão na qual Fichte toma partido com estes primeiros esboços de sua

doispontos, Curitiba, São Carlos, vol. 4, n. 1, p. 47-61, abril, 2007 
Doutrina da Ciência ${ }^{12}$. Sua carta a Reinhold de 28 de abril de 1795, claramente contemporânea da Doutrina da Ciência de 1794-5 (Grundlage), por exemplo, já seria uma clara e ótima contraprova da tese de Rockmore ${ }^{13}$. Mas ainda há outras razões em contrário. A própria Begriffsschrift é um texto que evidencia precisamente o contrário da tese "pragmática" defendida pela interpretação de Rockmore. Já no prefácio à primeira edição aparecem elementos que põem em xeque semelhante interpretação. De resto, tanto na carta a Reinhold como na Grundlage e na Begriffsschrift Fichte demonstra estar preocupado com o fundamento de todo o saber.

\section{Fichte sobre Kant e os céticos}

A primeira coisa que Fichte faz é confessar que foi "pela leitura dos novos céticos", especialmente de Schulze e Maimon, que se convenceu por completo "de que a filosofia (...) ainda não foi erguida ao patamar de uma ciência evidente" (FICHTE, 1971, SW, I, pp. 29). Trata-se de uma sorte de constatação cética em relação à filosofia crítica; pois se a filosofia em geral ainda não pode ser dita uma ciência com todas as letras, não podemos aceitar que a filosofia de Kant em particular cumprisse o que prometeu. Kant, na verdade, não teria achado "o curso seguro da ciência" para a Metafisica. Uma constatação que outros oponentes de Kant teriam gostado de fazer, e que nos lembra uma outra que Fichte fizera na Recensão do Enesidemo: o princípio de consciência reinholdiano não é nem pode ser o fundamento absoluto de todo o saber, mas, quando muito, do saber do ponto de vista teórico. Pois Reinhold havia sustentado que as inúmeras objeções erguidas contra a filosofia de Kant (sobretudo as que diziam respeito à disputa em torno das coisas em si) poderiam ser demovidas mediante a construção de um sistema de filosofia transcendental fundado sobre um princípio último e evidente; e Fichte concordava com isso, mas considerando que a Filosofia Elementar de Reinhold não tinha sido bem sucedida neste quesito. Ambos constatam, porém, tanto Fichte como Reinhold, assim como mais tarde Schelling e Hegel, que Kant apenas teria oferecido uma propedêutica, não o próprio Sistema. Este ainda estava por construir-se.

Tudo isso poderia dar a impressão de que Fichte seria uma espécie de cético sui generis, ou que ele seria contra Kant. Mas penso que os textos

doispontos, Curitiba, São Carlos, vol. 4, n. 1, p. 47-61, abril, 2007 
não apresentam nenhuma evidência de que Fichte fosse a favor de qualquer tipo de ceticismo: ele apenas aceitara que do ponto de vista puramente racional algumas objeções céticas podiam ser erguidas com todo o direito. Com relação a Kant, todavia, devemos conceder que a posição de Fichte é às vezes ambígua: ora desfaz-se em elogios, ora destila críticas. Assim, por exemplo, ainda neste prefácio à primeira edição da Begriffsschrift, Fichte nos confidencia que "até agora" está "intimamente convicto de que nenhum intelecto humano poderia ir além do limite a que Kant... confessou [chegar]...". Mas imediatamente acrescenta que Kant "nunca determinou para nós" este limite, "nem mostrou que era o limite último do conhecimento humano <des menschlichen Wissens $>$ ". E ainda que na frase seguinte declare que "ele nunca poderá dizer algo a que Kant, direta ou indiretamente, de modo mais claro ou mais obscuro, já não tenha feito referência <gedeutet habe > ", o leitor fica com a impressão de que para Fichte, no fundo, Kant não esclareceu de modo satisfatório quais sejam os limites do conhecimento humano. Em que medida semelhante situação permitiria sustentar que Fichte era um filósofo transcendental no sentido kantiano é um aspecto no mínimo problemático ${ }^{14}$. Principalmente quando se comparam as passagens acima citadas com outras da Primeira Introdução à Doutrina da Ciência (1797) ${ }^{15}$.

Em qualquer caso, o que se pode afirmar com certa segurança é que Fichte concorda com os céticos que muita coisa é objetável no empreendimento de Kant, e aceita com Reinhold que a única solução é reconstruir o sistema da filosofia transcendental a partir de um princípio último (cf. BONACCINI, 2003, pp. 52ss, 107ss, 157ss, 385ss ). Talvez por isso Fichte acreditasse "ter descoberto o fundamento $<$ Grund $>$ e um atalho <leichten Weg> para satisfazer completamente todas aquelas exigências dos céticos à filosofia crítica, por sinal muito bem fundadas..." (ibid.). Essa é precisamente a pretensão da sua Doutrina da Ciência.

\section{Fichte e a exigência de uma fundamentação última}

Se agora nos voltarmos para o texto em questão, poderemos ver que sua estrutura interna já corresponde por si só à de um programa, a um plano para a construção de um sistema definitivo do conhecimento humano.

doispontos, Curitiba, São Carlos, vol. 4, n. 1, p. 47-61, abril, 2007 
Assim, se desconsiderarmos a terceira seção da Begriffsschrift ("Divisão hipotética da Doutrina da Ciência”), tal como fez o próprio Fichte na edição de $1798^{16}$, poderemos dividir o texto em pelo menos três partes que apontam nessa direção. Essas partes poderiam ser definidas e classificadas conforme se segue.

A primeira parte está constituída pelos dois prefácios e a primeira seção $\left(\mathbb{S} 1^{\circ}-^{\circ}\right)$, na qual toda a problemática da Doutrina da Ciência é caracterizada em relação ao contexto das discussões da época, e retoma a tese reinholdiana da necessidade de um sistema fundado sobre um princípio único e absolutamente último; a segunda parte, é constituída pelo terceiro parágrafo $\left(\mathbb{S} 3^{\circ}\right)$, já na segunda seção do escrito, na qual o programa que em princípio se exigiria para uma exposição e solução suficientes dos problemas colocados nos parágrafos $\left(\mathbb{S} \int 1^{\circ}-2^{\circ}\right)$ é reformulado através de uma série de quatro questões intimamente relacionadas e logicamente conectadas entre si; e a terceira parte, por fim, é constituída pelos restantes parágrafos da segunda seção $\left(\mathbb{S} \int^{\circ}, 5^{\circ}, 6^{\circ}, 7^{\circ}\right)$, que tentam responder sistematicamente a essas quatro questões.

Por outro lado, salientando o teor fundamentalmente epistemológico da Doutrina da Ciência, Rockmore procura mostrar que Fichte não seria de modo algum um fundacionista, mas antes argumentaria contra o fundacionismo, através de uma

"hipótese introduzida com propósitos explicativos, a qual não pode ser verificada mediante [nenhuma] experiência de qualquer espécie, nem por intuição intelectual, visto que ela é a priori...O cogito que funciona como o fundamento na teoria cartesiana não é um mero postulado ou inferência conceitual, mas antes é diretamente dado na consciência...Porém, não existe semelhante fundamento na teoria fichteana...em que pese o que Fichte ou seus intérpretes possam pensar [?!], existe uma distinção básica entre hipótese, mesmo da espécie mais razoável e útil, de um lado, e de outro a simples idéia de um fundamento que pode funcionar como uma base para o conhecimento apodítico... Em seus escritos deste período, Fichte é explícito ao pretender que a filosofia, incluindo a sua, seja necessariamente hipotética.Vide 'Sobre o conceito da Wissenschaftslehre", [?!] (ROCKMORE, 1995, pp.118-119; grifo nosso) ${ }^{17}$. 
Ora, independentemente de saber se essa leitura de Descartes é correta ou não, e de determinar se Fichte fala ou não de uma "intuição intelectual" 18 do primeiro princípio absoluto de todo o conhecimento, temos pelo menos um fato: Fichte parece falar hipoteticamente não só porque ainda não construiu a ciência (a Doutrina da Ciência), i. é, porque ainda não a levou a cabo; mas, sobretudo, porque quer expor o "programa" de uma "nova" ciência. Esta nova ciência, por sua vez, pretende ser a ciência da ciência, a ciência de toda ciência. Trata-se, portanto, de um programa metafilosófico. De tal modo que antes de decidir-se contra ou a favor da ciência (filosófica), como os céticos, de decidir se há ou não ciência enquanto tal; antes de que a Doutrina da Ciência planejada seja desenvolvida em seus pormenores, enquanto o sistema ainda não foi construído, deve-se forçosamente falar programaticamente. Isto é, "idealmente", como se o objeto do discurso fosse "hipotético". Posta a "hipótese" como uma meta no espírito, é preciso encontrar os meios para realizá-la, as condições para sua consecução (Cf. FICHTE, 1971, SW, I, pp. 43-8). Mas isto não significa que toda a Doutrina da Ciência seja só e simplesmente uma empresa hipotética. Uma coisa é a ciência (a Doutrina da Ciência); outra a estratégia de argumentação que se usa para torná-la imune ao ataque dos céticos. Assim, um programa é irrefutável; o fracasso ou o sucesso de sua execução é que pode validá-lo ou invalidá-lo.

O raciocínio de Fichte poderia ser reconstruído da seguinte maneira: se há ciência, então ela deve existir sob certas condições (deve ser real de acordo com a sua possibilidade); se, entretanto, existe a ciência, então também deve existir um conhecimento, uma ciência destas condições unicamente sob as quais a ciência enquanto tal é possível. Se isso for correto, então ela deve ser considerada como a ciência da ciência, como uma teoria da cientificidade enquanto tal. Pois, em qualquer caso, ela deve ser um conhecimento de todas as condições fundamentais do conhecimento em geral (até aqui Fichte mantém-se como um fiel kantiano).

Acontece, porém, que esta ciência ainda não existe; portanto, ainda não sabemos se essa nossa meta é efetivamente realizável. O que é preciso para torná-la minimamente aceitável é que, como ciência da ciência, ela possa ser tida como conhecimento do conhecimento. Posto que nesse caso bastaria atestar algum conhecimento mínimo que possa ser reconhecido 
inegavelmente enquanto tal para que uma reflexão metadiscursiva sobre ele me permitisse deduzir a Doutrina da Ciência.

Por isso a questão de saber se existe realmente ciência, conhecimento real, ou não, surge de modo espontâneo; e como que se coloca por si só. Pois é evidente que em face do desafio dos céticos não podemos filosofar a partir de nenhum fato contingente, i. é, não podemos pressupor que existe realmente conhecimento e ciência. Por isso devemos encetar outra via e raciocinar inicialmente de modo hipotético.

Ora, na medida em que a ciência, se ela existir, deverá ser necessariamente um sistema (e isso tanto para Fichte como para toda a chamada aetas kantiana), a Doutrina da Ciência enquanto a ciência da ciência também deverá ser, por isso mesmo, um sistema.

Entretanto, parece que com isso ainda estamos de fato em face de duas possibilidades fundamentais: ou existe conhecimento real ou não existe. A resposta filosoficamente justificada a esta sorte de isostheneia implicaria conhecer o que está em questão, ter já respondido com sucesso à pergunta pela existência da cientificidade do conhecimento. Precisamente por isso deveríamos fazer uma espécie de Gedankenexperiment, e dizer: se existisse realmente conhecimento, e, a partir dele, a possibilidade real de um conhecimento (reflexivo) do conhecimento em geral, o qual, por sua vez, tal como em cada ciência particular e conhecimento enquanto tal, também constituísse um sistema, então, pergunta-se: sob quais condições poderíamos construir este sistema? Sob quais condições poderia ser levada a efeito a idéia de um sistema semelhante? Em princípio, isso é suficiente para montar o programa da Doutrina da Ciência. A execução, contudo provaria pelo ato aquilo que os céticos gostariam de questionar.

É isso o que Fichte tem em mente quando parece emitir um discurso "tão-somente hipotético" < allein hypotetisch>. O que não significa, por isso mesmo, que Fichte tenha considerado todo seu empreendimento como meramente hipotético. É o que se pode depreender de imediato a partir de uma breve passagem do prefácio a Begriffsschift:

“A investigação a seguir não ergue a pretensão a nenhuma outra validade que não seja hipotética. Mas disso não se segue de modo algum que o autor não possa pôr nada senão pressuposições infundadas na base de suas afirmações, nem que estas não devam ser os resultados de um sistema sólido e aprofundado" (FICHTE, 1971, SW I, p. 30; grifo nosso). 
Agora bem: como as afirmações do autor poderiam ser algo outro que não "afirmações infundadas" < unerwiesene Voraussetzungen>, portanto, sem uma fundamentação sólida, se elas já não fossem resultado de um sistema aprofundado e sólido < die Resultate eines tiefer gehenden und festen Systems seyn>? Como é que alguém poderia sequer falar de um "sistema sólido" sem já ter admitido de antemão a necessidade de uma fundamentação última $<$ Letzbegründung $>$ ? Esta é no fundo a grande dificuldade da interpretação de Rockmore: a Begriffsschrift de Fichte não corrobora sua tese, mas antes a refuta. Rockmore parece não obstante pensar que seria suficiente constatar que Fichte defendera a impossibilidade de uma prova dedutiva do primeiro princípio incondicionado mediante uma "estratégia circular" (já que não se pode provar o princípio sem cometer círculo) para concluir que Fichte não teria tencionado oferecer uma fundamentação última do princípio fundamental (cf. ROCKMORE, 1995, pp. 113 ss.). Todavia, a partir disso poderíamos concluir justamente o oposto, a saber, que a fundamentação última levada a cabo por Fichte consistiria na estratégia circular de uma demonstração indireta (porém dedutiva) do primeiro princípio da Doutrina da Ciência. Tratar-se-ia de mostrar que enquanto pressuposição necessariamente inevitável o princípio mesmo não poderia ser negado sob pena de contradição ${ }^{19}$.

Se Fichte não tivesse tido por alvo uma fundamentação última, por que teria então falado de um "princípio absolutamente primeiro" para o seu sistema? Como Fichte poderia ter procurado por este princípio e discorrido sobre ele sem ter pressuposto primeiro, i. é, a priori, a possibilidade de uma fundamentação última e completa de todo seu sistema a partir de um fundamento?

Não parece poder ajudar muito alegar que na Doutrina da Ciência de Iena Fichte estava comprometido com uma "ciência sistemática sem qualquer fundamento <systematic science without a foundation >" (ROCKMORE, 1995, p. 120). Particularmente porque o texto citado para apoiar a mencionada alegação, a saber, a Begriffsschrift, revela precisamente o contrário, a saber, que Fichte no fundo estava comprometido com uma concepção kantiana de sistema. Uma concepção conforme a qual apenas a unidade dos conhecimentos conectados a partir de um princípio racional e inegável é que constitui o conhecimento científico ${ }^{20}$.

doispontos, Curitiba, São Carlos, vol. 4, n. 1, p. 47-61, abril, 2007 


\section{Conclusão}

De resto, afora o problema acima mencionado, talvez devêssemos dizer em última instância, como o Prof. Breazeale (apud ROCKMORE, 1995, pp. 116s), que a estratégia circular da argumentação fichteana, particularmente na Begriffsschrift, é inteiramente compatível com a possibilidade e a necessidade de uma fundamentação última. Com isso, porém, ainda fica em aberto o problema mencionado por Rockmore da intuição intelectual como possível meio de acesso ao princípio último (Ibid. pp. 117ss.). Em que pese isso, neste contexto podemos assegurar, sobretudo em relação à Begriffsschrift, na qual Fichte discute sobretudo com Reinhold, Maimon e Schulze, que o acesso a este princípio absolutamente primeiro da Doutrina da Ciência é conquistado mediante uma análise de condições a partir de um fato de consciência que se apresenta como uma evidência (como, por exemplo, "Sei que P") ${ }^{21}$. É claro que este fato consciente será posteriormente reconhecido mediante reflexão (a saber, a execução do sistema) como realmente existente. Hipotética, contudo, é apenas a suposição epistêmica inicial conforme a qual existe conhecimento enquanto tal. Pois Fichte considera essa suposição, por sua vez, como necessária. Para que a proposição "Sei que P" possa ser tomada como verdadeira é preciso antes de mais nada ter admitido a possibilidade real do conhecimento em geral. Mas isso pode não ser uma grave problema, já que nenhum dos céticos oponentes poderia negar sua evidência ao constatar "Sei que P".

Apesar do que acabamos de defender, deve-se confessar que a problemática do antifundacionismo destacada por Rockmore, embora possa não corresponder literalmente com as conseqüências que ele extrai da obra em questão, deveriam todavia ser consideradas pelo menos como relevantes e sugestivas para a filosofia atual, que em sua maioria parece não mais aceitar a possibilidade de uma fundamentação última. Se isto pudesse expressar o lucro filosófico do esforço do prof. Rockmore, penso que ele teria atingido a sua meta. Isso, em nosso contexto, já seria um mérito considerável.

doispontos, Curitiba, São Carlos, vol. 4, n. 1, p. 47-61, abril, 2007 


\section{8}

1 Über den Begriff der Wissenschaftslehre - oder der sogenannte Philosophie (Jena, 1794), SW I, pp. 29-81 ("SW" abrevia as Fichtes Sämtliche Werke. Hrsg. von I. H. Fichte (Berlin:Veit \& Camp, 1845ss), Berlin:W. de Gruyter\& Co. 1971). A edição crítica mais recente é a da Gesamtausgabe der Bayerischen Akademie der Wissenschaften, Hrsg. von R. Lauth u. H. Jacob. Stuttgart/BadCannstadt, Frommann-Holzboog, 1962-ss. Aqui, salvo indicação explícita, citarei a SW, seguida do número do volume em números romanos e da página em arábicos.Vale lembrar que da Begriffschrift há uma boa tradução para a língua portuguesa feita por Rubens Rodrigues Torres Filho (Sobre o conceito da Doutrina-da-Ciência, ou da assim chamada Filosofia, in: Fichte/Schelling: Escritos Filosóficos, Coleção “Os Pensadores”, São Paulo, 1973, pp. 9-37), a qual reproduz a segunda edição (Gabler, Jena und Leipzig, 1802).

2 Cf. Fichte a F.A. Weisshun, julho de 1794. Apud Daniel Breazeale, 1992, pp. 5-6.

3 A saber, o Fundamento de toda a Doutrina da Ciência (Grundlage der gesammten Wissenschaftslehre, Leipzig, C. Gabler, 1794-5).

${ }^{4}$ Isso não acontece somente na literatura americana ou européia sobre Fichte, mas inclusive entre nós. Assim, um trabalho monumental como o de R. Rodrigues TORRES FILHO (1975) não se detém a tematizá-lo enquanto tal, embora seu primeiro capítulo (pp. 25-75) cite a Begriffsschrift nada menos que setenta e duas vezes (!) e ancore boa parte de sua interpretação em seus conceitos. Tampouco nosso recente trabalho (BONACCINI, 2003, pp.107-116) oferece dela uma tematização explícita no capítulo dedicado a Fichte (ainda que a cite).

5 É o caso de TORRES FILHO (cf. 1975, pp. 127ss, 176ss) e J. RIVELAYGUE (1990, I 156ss), por exemplo. Sobre a Grundlage, afora a tradução existente de Torres Filho na coleção “Os pensadores” (São Paulo, Abril, 1983), tenho à mão a edição de Medicus: Grundlage der gesamten Wissenschaftslehre (Leipzig, C. Gabler). Neu hrsg. von F. Medicus. Leipzig: F. Meiner. Zweite Auflage: 1922.

6 Cf. Daniel Breazeale (1992).

7 Cf. por exemplo: K. HAMMACHER, 1981; Marek J. SIEMEK, 1984; R. F. KOCH, 1989; J. BRACHTENDORF, 1995.

8 Fichte a Reinhold, 28 de abril de 1795 (1962, GA, III/2, p. 315). Cf. BONACCINI 2003, pp. 107, 387.Veja-se também pp. 52ss, 157 ss.

${ }^{9}$ M. GERTEN escreveu recentemente um excelente artigo sobre isso (1997, pp. 173-189).

10 É preciso reconhecer, não obstante, que embora Rockmore considere sua tese (conforme a qual Fichte na verdade seria um "antifoundationalist") válida para o período de Iena, ela é proposta sobretudo em referência a Grundlage de 1794-95. Assim, aparentemente, nada teria a ver com o propósito principal de nossa presente nota. Não obstante isso, é preciso lembrar que o próprio Rockmore apela a Begriffsschrift para fundamentar sua interpretação. Por isso a discussão com Rockmore tem uma significação que é relevante para a interpretação da estratégia anticéptica de Fichte na Begriffsschrift.

11 "O autor deste tratado foi persuadido por completo através da leitura dos novos céticos, em particular de Enesidemo [Schulze] e dos excelentes escritos de Maimon (...) que a filosofia, mesmo através dos mais recentes esforços dos homens mais perspicazes, ainda não foi

doispontos, Curitiba, São Carlos, vol. 4, n. 1, p. 47-61, abril, 2007 
alçada ao patamar de uma ciência evidente" (Der Verfasser dieser Abhandlung wurde durch das Lesen neuer Skeptiker, besonders des Aenesidemus und der vortrefflichen Maimonischen Schriften völlig von dem überzengt...dass die Philosophie, selbst durch die neuesten Bemühungen der scharfsinnigsten männer, noch nicht zum Range einer evidenten Wissenschaft erhoben sey) (FICHTE, 1971, SW I, 29). Sobre isso ver HORSTMANN, 1995, pp. 107ss.

12 Cf. HORSTMANN, 1995, pp. 49ss, 69ss, especialmente pp. 104-130. Veja-se também BONACCINI, 2003, pp. 107ss; BREAZEALE, 1993, apud ROCKMORE, 1995, p.117; DOMINGUEZ, 1982, pp.16s; RIBEIRO DOS SANTOS, 2007, pp. 273ss.

${ }^{13}$ Ver FICHTE, 1962, GA, III, 2, pp. 314-315.Veja-se ainda a Recension (FICHTE, 1971, SW, I, $5,8,10)$. Neste contexto Fichte fala sobre o círculo, mas ele se expressa diferentemente do que advoga a interpretação de Rockmore (FICHTE, 1971, SW I, 11 e 19-20). Cf. ainda FICHTE, 1971, SW, I, 61-2, 72-3.

14 Bernabé NAVARRO defende essa idéia em seu estudo de 1971.

$15 \mathrm{Na}$ "Apresentação" < Vorerinnerung> Fichte dizia que queria "consagrar sua vida a uma exposição totalmente independente daquela grande descoberta de Kant < sein Leben einer von Kant ganz unabhängigen Darstellung jener grossen Entdeckung zu widmen>" (FICHTE, 1971, SW I, 419). Cf. Ibid. pp. 419-21 e a Segunda Introdução à Doutrina da Ciência (ibid. pp. 468ss).

16 Sobre isso veja-se a Grundlage, Prefácio < Vorbericht> à primeira edição, FICHTE, 1971, SW I, pp. 86ss.

17 As últimas duas frases do parágrafo citado são de uma nota de rodapé (n. 43) à página 119, que aparece respectivamente na p. 124.

18 D. Henrich defendeu a tese contrária numa Preleção em Heidelberg de 1965/66, a saber, que Fichte (como Hegel e Schelling) teria partido da evidência cartesiana de nossa certeza de si como o fundamento de todas as outras proposições dela derivadas (Ver M. FRANK, 1985, p. 24). Sobre a problemática da intuição intelectual veja-se: A. PHILONENKO, 1982, pp. 91ss; F. INCIARTE, 1970, pp. 46ss, 55ss, 103ss;W.WEISCHEDEL, 1973; R. F. KOCH, 1989, pp. 105ss.

19 O que nos lembra ligeiramente, apesar de todas as diferenças em jogo, a refutação aristotélica daquele que se propusesse a negar o princípio de não-contradição na Metafísica $\left(^{\circ}, 4\right.$, 1006 a 28 - b 34).

${ }^{20}$ Vide Begriffsschrift, $\$ 1$ (FICHTE, 1971, SW, I, p. 38); KANT, 1902 ss., KrV, A832/B860. Cf. B24ss, B27ss, A80ss/B106ss, A645/B673.

21 Assim Fichte diz, por exemplo no prefácio à segunda edição da Begriffsschrift, que a Doutrina da Ciência deve ser "uma derivação genética daquilo que ocorre em nossa consciência" <eine genetische Ableitung dessen, was in unserem Bewusstsein vorkommt...> (FICHTE, 1971, SW, I, p. 32). Rockmore parece aceitar algo semelhante (1995, p.118), mas sempre no contexto de sua defesa do caráter hipotético da Doutrina da Ciência. Nós pensamos que o programa de Fichte, enquanto plano de uma obra sistemática a ser executada, seria per se essencialmente hipotético; mas vale lembrar que o sistema almejado, a Doutrina da Ciência, não é em si nem pode ser uma hipótese, mas antes uma estrutura necessária geneticamente derivada (ou derivável) a partir de uma fato indiscutível e de modo algum admitido hipoteticamente. Todavia, essa estrutura, enquanto estrutura conceitual, é ambígua; pois de início diz simultaneamente respeito tanto ao

doispontos, Curitiba, São Carlos, vol. 4, n. 1, p. 47-61, abril, 2007 
todo representado e figurado do sistema do conhecimento humano, i.e. à Doutrina da Ciência, quanto ao "sistema" no conhecimento humano mesmo, ao próprio conhecimento no espírito como um organon (cp. KANT, 1902 ss., KrV, BXXXVII-VIII), o que é definido às vezes como Tathandlung e eu absoluto. Como contra-argumento parece por isso insatisfatório assegurar que somente a linguagem de Fichte seria fundacionista, mas não sua estratégia.

\section{Referências bibliográficas}

BONACCINI, J. A. 2003. Kant e o problema da coisa em si no Idealismo Alemão, Rio, Relume-Dumará.

BRACHTENDORF, J. 1995. Fichtes Lehre vom Sein. Eine kritische Darstellung der Wissenschaftslehren von 1794, 1798/99 und 1812. Paderborn (Schöningh)

BREAZEALE, D. 1992. (ed. and transl) Fichte. Foundations of Transcendental Philosophy. (Wissenschaftslehre) nova methodo (1796/99), Ithaca: Cornell Univ. Press.

BREAZEALE, D. 1993. "Circles and Grounds in the Jena Wissenschaftslehre", in: Fichte: Historical Context and Contemporary Controversies. Ed. by D. Breazeale and T. Rockmore, Atlantic Highlands/NJ.

DOMINGUEZ,V. E. L. 1982. La concepción fichteana del amor. $2^{\mathrm{a}}$. Ed. Buenos Aires, Sudamericana.

FICHTE, J. G. 1922 (hrsg.: F. Medicus) J.G. Fichtes Grundlage der gesamten Wissenschaftslehre (Leipzig, C. Gabler). Zweite Auflage. Neu hrsg. von F. Medicus. Leipzig: F. Meiner.

FICHTE, J. G. 1973. Fichte/Schelling: Escritos Filosóficos, Coleção "Os Pensadores", São Paulo.

FICHTE, J. G. 1971. Fichtes Sämtliche Werke. Hrsg. von I. H. Fichte (Berlin:Veit \& Camp), Berlin:W. de Gruyter\& Co.

FICHTE, J. G. 1962ss. Gesamtausgabe der Bayerischen Akademie der Wissenschaften, Hrsg. von R. Lauth u. H. Jacob. Stuttgart/BadCannstadt, Frommann-Holzboog. 
FRANK, M. 1985. Eine Einführung in Schellings Philosophie. Frankfurt am Main. GERTEN, M. 1997. "Fichtes Wissenschaftslehre vor der aktuellen Diskussion um die Letztbegründung”, in: Fichte-Studien 13, pp. 173-189. HAMMACHER, K. 1981. (Hrsg.) Der transzendentale Gedanke. Die gegenwärtige Darstellung der Philosophie Fichtes, Hamburg, F. Meiner. HORSTMANN, R-P. 1995. Die Grenzen der Vernunft, 2a. Ed. Weiheim, Beltz Athenäum.

INICIARTE, F. 1970. Transzendentale Einbildungskraft, Bonn, Bouvier.

KANT, I. 1902ss. Kants gesammelte Schriften, Ed. da Academia Prussiana das Ciências, Berlin, G. Reimer.

KOCH, Reinhard F. 1989. Fichtes Theorie des Selbstbewusstseins. Würzburg, Königshausen \& Neumann.

NAVARRO, B. 1971. El desarrollo fichteano del Idealismo Trascendental de Kant, México, Fondo de Cultura Económica.

PHILONENKO, A. 1982. "Die Intellektuelle Anschauung bei Fichte", in: K. Hammacher (hrsg.), Der Transzendentale Gedanke. Die gegenwärtige Darstellung der Philosophie Fichtes, , Hamburg: Meiner.

SANTOS, R. L. 2007. O Espírito da Letra. Ensaios de Hermenêutica da Modernidade, Lisboa: Imprensa Nacional-Casa da Moeda.

RIVELAYGUE, J. 1990 Leçons de métaphysique allemande, Paris: Le Collège de Philosophie/Grasset.

ROCKMORE, T. 1995 "Fichtean Circularity, Antifoundationalism and Groundless System”, in: Idealistic Studies, v. 25, n. 1, pp. 107-124.

SIEMEK, M. J. 1984 Die Idee des Transzendentalismus bei Fichte und Kant, Hamburg: F. Meiner.

TORRES FILHO, R. R. 1975 O Espírito e a Letra. A Crítica da Imaginação Pura em Fichte. São Paulo: Ática.

WEISCHEDEL, W. 1973 Der Frühe Fichte, zweite Auflage, StuttgartBad Cannstatt: Frommann-Holzboog. 
○

0 